\title{
Effect of hydrogen charging on the mechanical properties of medium strength aluminium alloys 2091 and 2014
}

\author{
AMIT BANDYOPADHYAY, RAJAN AMBAT and \\ E S DWARAKADASA \\ Department of Metallurgy, Indian Institute of Science, Bangalore 560012, India \\ MS received 11 September 1991; revised 30 March 1992
}

\begin{abstract}
Cathodic hydrogen charging in $3.5 \% \mathrm{NaCl}$ solution altered the mechanical properties of $2091-\mathrm{T} 351\left(\mathrm{Al}-\mathrm{Cu}-\mathrm{Li}-\mathrm{Mg}-\mathrm{Zr}\right.$ ) determined by a slow $\left(10^{-3} / \mathrm{s}\right)$ strain rate tensile testing technique. UTS and YS decreased in the case of 2091-T351 and 2014-T6(Al-Cu-Mn$\mathrm{Si}-\mathrm{Mg}$ ) with increase in charging current density. Elongation showed a decrease with increase in charging current density for both the alloys. However, elongation occurring throughout the gauge length in uncharged specimens changed over to localized deformation, thus increasing the reduction in area in charged specimens. A transition in fracture mode from surface (brittle) to the core (ductile) was observed. The presence of hydrogen increased the hardness, mostly indicative of solution strengthening and it decreased with depth confirming the existence of hydrogen concentration gradient. The effects were similar in 2014-T6, but to a slightly smaller extent.
\end{abstract}

Keywords. Hydrogen charging; aluminium alloys; mechanical properties; microhardness.

\section{Introduction}

Aluminium alloys are getting revived attention because of the possibility of further improving the strength-to-weight ratio in competition with composites, intermetallics and titanium alloys. Presently the focus is on low-density high-stiffness materials with better mechanical properties. As with every $1 \mathrm{wt} \%$ addition of $\mathrm{Li}$ to $\mathrm{Al}$ (up to $4 \mathrm{wt} \%$ of Li) the density decreases by $3 \%$ improving the stiffness by $6 \%$ (Sankaran and Grant 1980). The aluminium-lithium ( $\mathrm{Al}-\mathrm{Li})$ alloys have received much attention in the last decade or so. Moreover, relative to fibre reinforced composite materials, $\mathrm{Al}-\mathrm{Li}$ alloys can be more easily manufactured and fabricated using existing facilities, which will lower the manufacturing costs (Lavernia et al 1990).

The addition of $\mathrm{Li}$ to $\mathrm{Al}$ leads to the formation of metastable $\delta(\mathrm{AlLi})$ and $\delta^{\prime}\left(\mathrm{Al}_{3} \mathrm{Li}\right)$ precipitates, of which $\delta^{\prime}$ is the main strengthening precipitate with an ordered $\mathrm{Ll}_{2}$ superlattice structure. Electrochemically these precipitates are anodic to the matrix. $\mathrm{Cu}$ and $\mathrm{Mg}$ addition improves the overall strength by co-precipitating with $\delta^{\prime}$ and/or incorporating $\mathrm{Li}$ to form coherent and partially coherent ternary and more complex matrix-strengthening precipitates. Co-precipitation of partially coherent phases is beneficial because in addition to improving the strength of the alloy it also promotes homogeneous deformation (Hill et al 1984). Moreover $S$ and $S^{\prime}$ phases formed by $\mathrm{Mg}$ addition help to minimize the formation of precipitate-free zone (PFZ). $\mathrm{Zr}$ addition to $\mathrm{Al}-\mathrm{Li}$ alloys helps to get a fine-grained structure with the formation of $\mathrm{Al}_{3} \mathrm{Zr}\left(\beta^{\prime}, \mathrm{Ll}_{2}\right)$, which can pin down the grain boundary effectively and retard recrystallization.

Since Al--Li alloys are being considered as candidate materials for hydrogen fuel tanks in the space shuttle and the proposed hypersonic and transatmospheric vehicles, it is important to understand the hydrogen embrittlement phenomena in these alloys. 
However the present understanding about the effect of hydrogen on mechanical properties of $\mathrm{Al}-\mathrm{Li}$ alloys both at cryogenic and room temperature (Hills et al 1984) appears to be limited. Al-Li alloys have been known to be susceptible to environmental-assisted cracking (Sater and Sanders 1989; Meletis and Huang 1989; Rivet and Swanson 1989). In structural applications hydrogen content increases in these alloys during several thermal treatments like heat treatment, welding etc. (Pickens 1985). The effect of cathodic charging of hydrogen on the mechanical properties of $\mathrm{Al}-\mathrm{Li}$ alloys has been studied by a few investigators (Watson et al 1988; Shin et al 1989). Watson et al (1988) observed that due to cathodic charging in aluminium alloys, failure occurred in a completely ductile manner with very high reduction in area and the effect was found to increase with increasing charging time but decreased with decreasing test temperature (Shin et $\dot{a}$ l 1989) in the case of $\mathrm{Al}-\mathrm{Li}$ alloys. In general $\mathrm{Al}-\mathrm{Li}$ alloys have been shown to retain larger amounts of hydrogen than what normally occurs in other high strength aluminium alloys not containing lithium. This probably is due either to an increase in solid solubility of hydrogen in the lithiumalloyed matrix or the formation of hydrogen-rich phases or both. Hills and Williams (1984) proposed that the poor ductility in $\mathrm{Al}-\mathrm{Li}$ alloys may be explained because of the formation of a stable hydride either of lithium $(\mathrm{LiH})$ or of $\mathrm{Al}$ and $\mathrm{Li}\left(\mathrm{Li}_{3} \mathrm{AlH}_{6}\right)$. But Palmer et al (1984) found no difference between the mechanical properties of P/Mprocessed $\mathrm{Al}-\mathrm{Li}$ alloys of almost the same composition containing $46 \mathrm{ppm}$ and 1-3 ppm hydrogen. An overall comparison of available data does not show any precise conclusion about the effect of hydrogen on the mechanical properties of $\mathrm{Al}-\mathrm{Li}$ alloys. In the present study the effect of cathodic charging of hydrogen in $3.5 \% \mathrm{NaCl}$ solution on the mechanical properties of an Al- $\mathrm{Li}$ alloy 2091-T351 was studied and compared with that in a standard aircraft alloy 2014-T6 using a slow strain rate tensile testing technique.

\section{Materials and experimental procedure}

Commercial $\mathrm{Al}-\mathrm{Li}-\mathrm{Cu}-\mathrm{Mg}-\mathrm{Zr}$ alloy conforming to 2091 was purchased from Pechiney, France and was in sheet form heat-treated to T351 temper (i.e. solutionized, deformed to give $2-3 \%$ plastic deformation and then naturally aged to substantially stable condition). For comparison a standard high strength aircraft alloy 2014 in T6 temper (i.e. solutionized and then peak-aged at $453 \pm 1 \mathrm{~K}$ for $16-20 \mathrm{~h}$ ) was included. The thickness of the sheets was $2 \mathrm{~mm}$. The chemical composition ranges of these two alloys as certified by the supplier were:

$\begin{array}{lccccccc} & \mathrm{Cu} & \mathrm{Li} & \mathrm{Mg} & \mathrm{Si} & \mathrm{Fe} & \mathrm{Zr} & \text { Others } \\ \text { 2091-T351 } & 2 \cdot 1 & 1.8 & 1.1 & 0.04 & 0.04 & 0.1 & 0.1 \\ \text { 2014-T6 } & 4.4 & - & 0.5 & 0.8 & - & - & 0.8(\mathrm{Mn})\end{array}$

Tensile specimens were milled out from large sheets such that the tensile axis of the specimen was always parallel to the rolling direction.

To study the effect of hydrogen on the mechanical properties of the present set of alloys, the specimens were cathodically charged as it represents the most severe charging and is known to produce the most deleterious effect on properties (Meletis and Huang 1989). Charging was carried out with increasing charging current density 
(ccd) using a galvanostatic circuit and a D.C. power source in $3 \cdot 5 \% \mathrm{NaCi}$ solution of $\mathrm{pH}$ 6.2 for $10 \mathrm{~h}$. The solution temperature was maintained constant during charging at $45^{\circ} \mathrm{C}$ with the help of a thermostatically-controlled water bath. It may be noted that the severity of hydrogen diffusion into the specimen is higher in solutions of lower $\mathrm{pH}$. However various aeronautical alloys were being studied for their corrosion behaviour in near neutral $\mathrm{NaCl}$ solution. Also in an earlier study (Rajan Ambat and Dwarakadasa 1991 ) it has been realized that rates of metal dissolution in low pH solution were high. Further, in practice, various cleaning procedures for this material are also in slightly acidic solutions. It was therefore decided to use $3.5 \% \mathrm{NaCl}$ solution at $\mathrm{pH} 6.2$ as the electrolyte. However in order to complete this study, the effect of hydrogen as a function of $\mathrm{pH}$ was studied separately. Immediately after charging the specimens were thoroughly cleaned. During charging a thin layer of dark-coloured material was formed on the specimen. This was removed by grinding on 600 grade emery paper before testing such that the emery marks were along the tensile axis and did not influence the tensile strength. However in most specimens the thickness of the material removed was not greater than 5-8 $\mu \mathrm{m}$. In view of the fact that the thickness to which the effect of hydrogen was more than $100 \mu \mathrm{m}$ (figure $3 \mathrm{~b}$ ) this procedure is not likely to significantly alter the mechanical behaviour. Tensile tests were conducted on a servo hydraulic testing machine (Instron 8032) at a strain rate of $0.001 \mathrm{~s}^{-1}$. Fracture surfaces were observed with a scanning electron microscope (JEOL 840A) for obtaining the fractographic features. To find out the hydrogen concentration profile in the material microhardness was measured on the cross-section of the charged specimen at different depths using a Tucon microhardness tester. In each case three specimens were tested and the average value used for making the plots. However, the scatter in data points was approximately within $5 \%$ of the average value.

\section{Results and discussion}

\subsection{Effect on tensile properties}

Figure 1 shows the variation of ultimate tensile stress (UTS) and yield stress (YS) (corresponding to $0 \cdot 2 \%$ strain) vs ccd. It can be seen that when ccd increases there is a drop in the UTS and YS values for both the alloys. In the case of 2091-T351 a saturation in the drop of UTS and YS was observed above a ccd $10 \mathrm{~mA} / \mathrm{cm}^{2}$, but for 2014-T6, there was excessive dissolution of the alloy above $10 \mathrm{~mA} / \mathrm{cm}^{2}$ making it practically impossible to continue the charging. Figure $2 \mathrm{a}$ shows the percentage variation of elongation and figure $2 b$ the percentage variation of reduction in area (RA) vs ccd. In both cases elongation decreases with increasing ccd i.e. with increase in hydrogen concentration in the material. However, RA increased with increasing ccd. It has also been observed that in the case of hydrogen-charged specimens deformation occurred at a more localized region resulting in necking which effectively increases RA. The necking phenomenon is directly proportional to ccd.

\subsection{Microhardness measurements}

As ccd increases, the rate of hydrogen evolution will be larger and as a result the amount of hydrogen diffusing into the specimen will also be greater. The maximum 


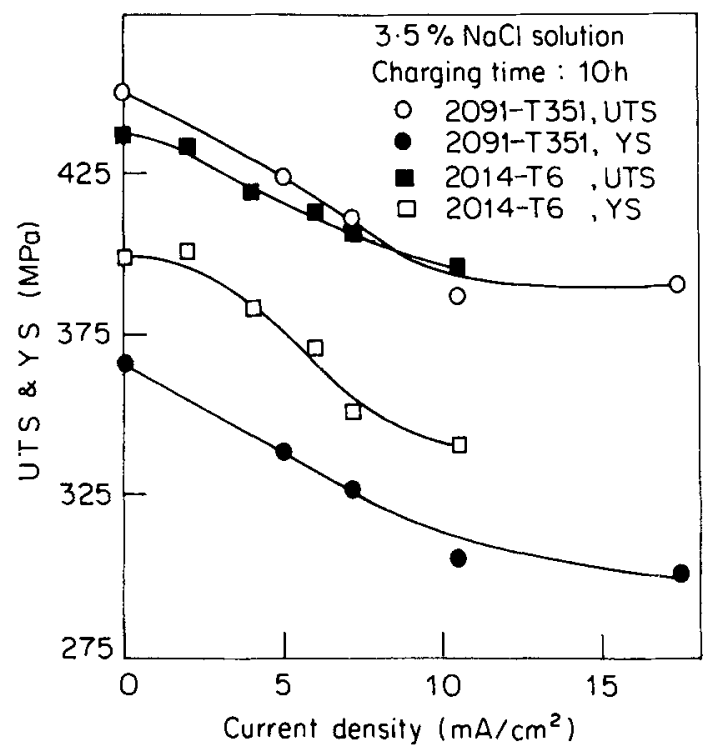

Figure 1. Effect of hydrogen charging (current density) on UTS and YS.

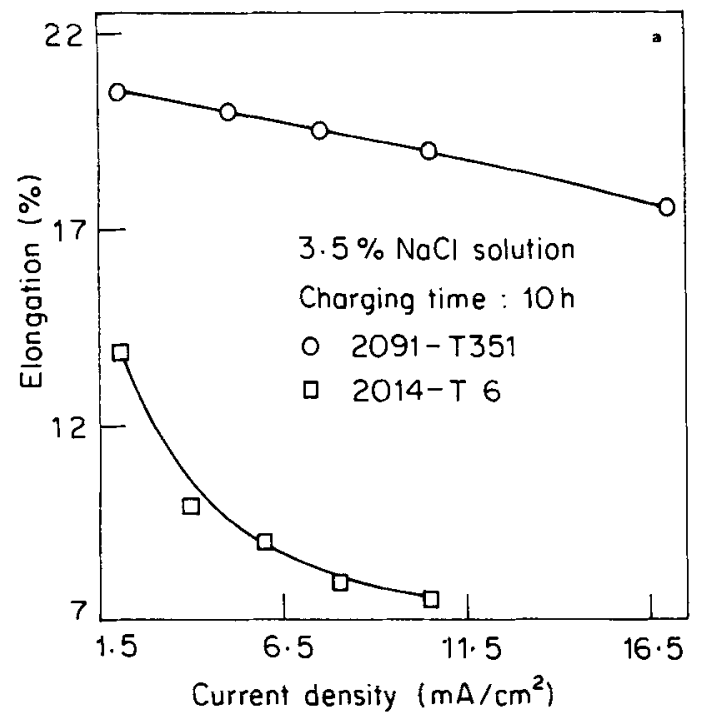

Figure 2a. Effect of hydrogen charging (current density) on elongation.

concentration of hydrogen is on the surface of the specimen and gradually decreases to the core. The concentration profile of hydrogen can be indirectly obtained from microhardness measurements at different depths, because increase in hydrogen concentration also leads to an increase in the hardness value. In the present work microhardness was measured on both the materials (2091-T351 and 2014-T6) to find out the hydrogen concentration profile (figure $3 \mathrm{a}, \mathrm{b}$ ). With increasing ced the surface microhardness value increased and it gradually decreased with depth to attain a constant value at some depth. The depth at which the hardness became constant also 


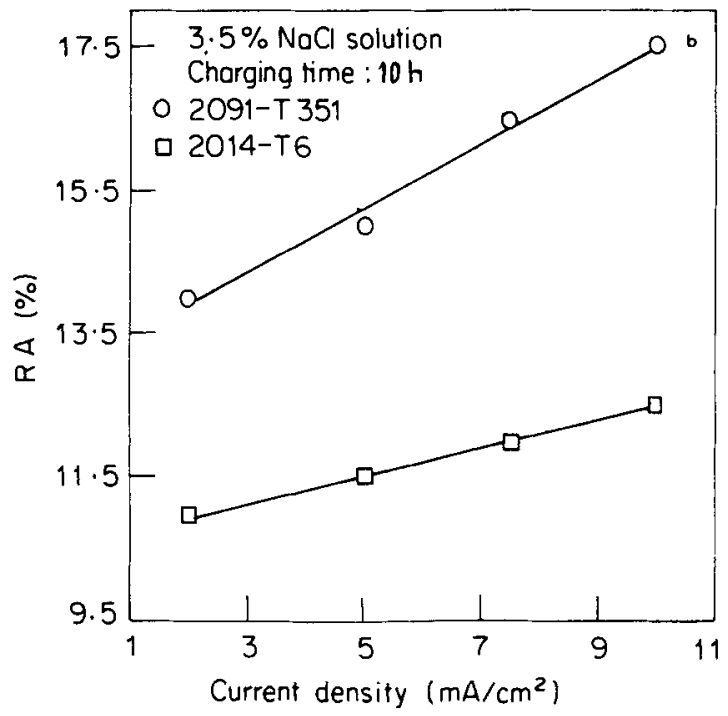

Figure 2b. Effect of hydrogen charging (current density) on RA.
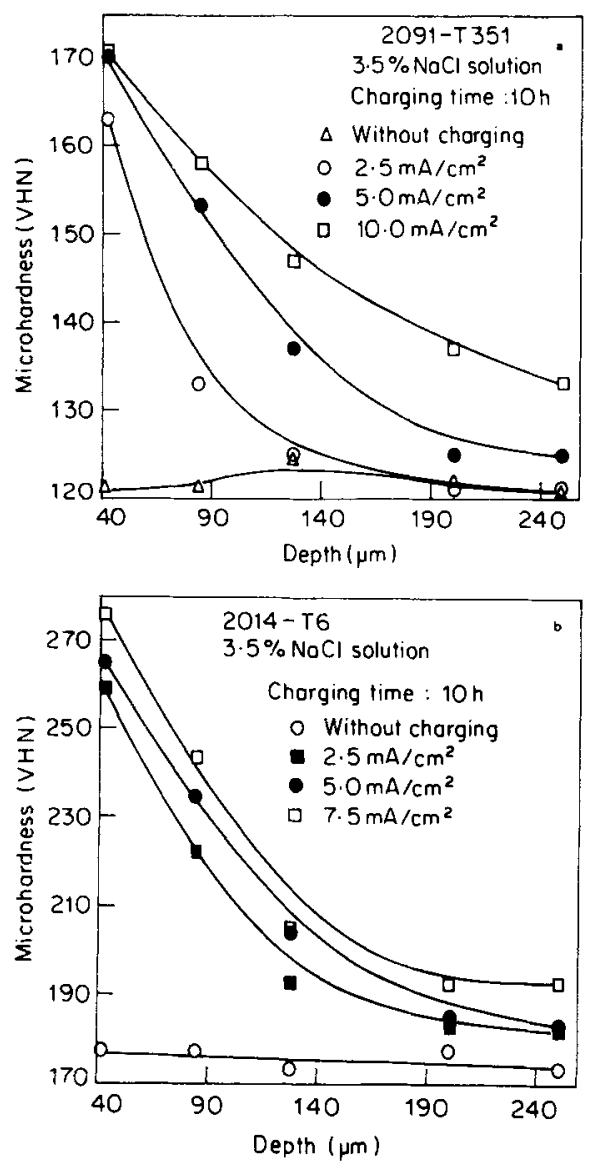

Figure 3. Effect of hydrogen charging (current density) on microhardness (a) 2091-T351 and (b) 2014-T6. 
increases with increasing ccd. This change was more pronounced for 2091-T351 than for 2014-T6. In the case of 2014-T6, the depth of saturation remained almost the same up to $10 \mathrm{~mA} / \mathrm{cm}^{2}$. For 2014-T6 the change in microhardness value followed a limited range and the initial increase with ced in microhardness value was larger, but subsequently this change became low compared to that in 2091-T351. The high value of hardness observed at the surface and the gradual decrease with increase in depth is due to the change in concentration of hydrogen at different depths depending upon the diffusivity of hydrogen in the material. The hydrogen present in the lattice can directly contribute to solution-strengthening by hydrogen. Increase in ccd increases the surface concentration of hydrogen and a corresponding increase in the concentration of hydrogen inside the material leading to a shift in the curve to higher hardness values. The difference in behaviour observed in 2091-T351 and 2014-T6 cannot be easily explained as both the alloys have similar composition except for the presence of lithium. The exact mechanism of the increase in hardness value is still not clear. There is a speculation that due to the formation of hard phases like $\mathrm{LiH}$ or $\mathrm{Li}_{3} \mathrm{AlH}_{6}$, the hardness increases. The present observation contradicts this concept of formation of metallic hydrides because the material is found to regain its original hardness value after degassing at a temperature far below the decomposition temperature of hydrides. In another case (Armacanqui and Oriani 1987), it was reported that increase in hydrogen concentration results in an increase in the dislocation density, which in turn increases the hardness value.

\subsection{Fractography}

Fractographic features of both the alloys clearly depict embrittlement near the surface due to hydrogen charging. In the core region the failure is dominated by large dimples, indicative of ductile failure. Figures $4 a$ and $b$ show the fractographic features of 2091-T351 and 2014-T6 in the deeper regions. In the case of figure 4a, charged at $10 \mathrm{~mA} / \mathrm{cm}^{2}$, large ductile dimples with planar slip facets are evident, which is typical of $\mathrm{Al}-\mathrm{Li}$ alloys. In $2014-\mathrm{T} 6$ charged at $7.5 \mathrm{~mA} / \mathrm{cm}^{2}$ (figure $4 \mathrm{~b}$ ), only large ductile dimples were observed. In both cases (figures $5 \mathrm{a}, \mathrm{b}$ ), there is a change in the fracture mode from surface to inside i.e. a brittle cleavage mode to ductile microvoid coalescence. From the fractograph it is possible to measure the depth to which the brittle mode of fracture is exhibited (approximately $25-30 \mu \mathrm{m}$ in 2014-T6 and about $20 \mu \mathrm{m}$ in the case of 2091-T3). Figure 3a shows a large hydrogen concentration at much larger depths in the specimen possibly pointing to the fact that in order to cause embrittlement, the concentration has to be above a certain critical value. With the limited number of experiments conducted here, this could not be established with certainty and is presently being looked into.

\section{Conclusions}

(i) Increase in hydrogen concentration by cathodic charging at $45^{\circ} \mathrm{C}$, decreased UTS, YS and elongation for both 2091-T351 and 2014-T6 alloys, whereas RA was found to increase.

(ii) A transition from brittle to ductile fracture was observed from the surface to the interior. 

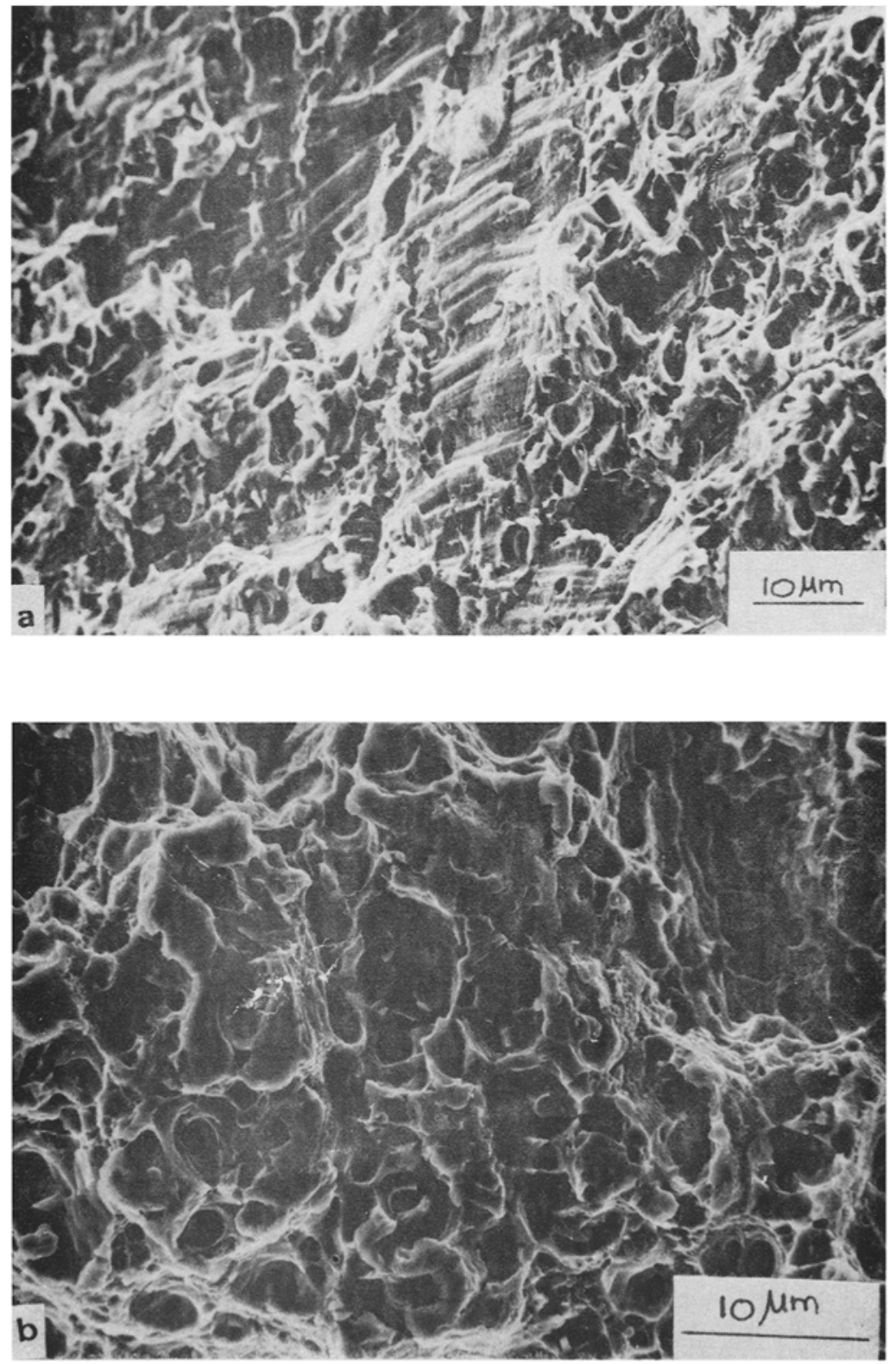

Figure 4. a. SEM fractograph of the inside region of the 2091-T351 sample charged at $10 \mathrm{~mA} / \mathrm{cm}^{2}$. Fracture surface exhibits a combination of planar facets with large dimples. b. SEM fractograph of the inside region of the 2014-T6 sample charged at $2 \mathrm{~mA} / \mathrm{cm}^{2}$. Fracture surface exhibits large dimples.

(iii) Microhardness measurements showed an increase in hardness with charging current density and the hardness decreased with depth. In both cases the material was found to regain its hardness after degassing confirming the absence of any hydride formation. 

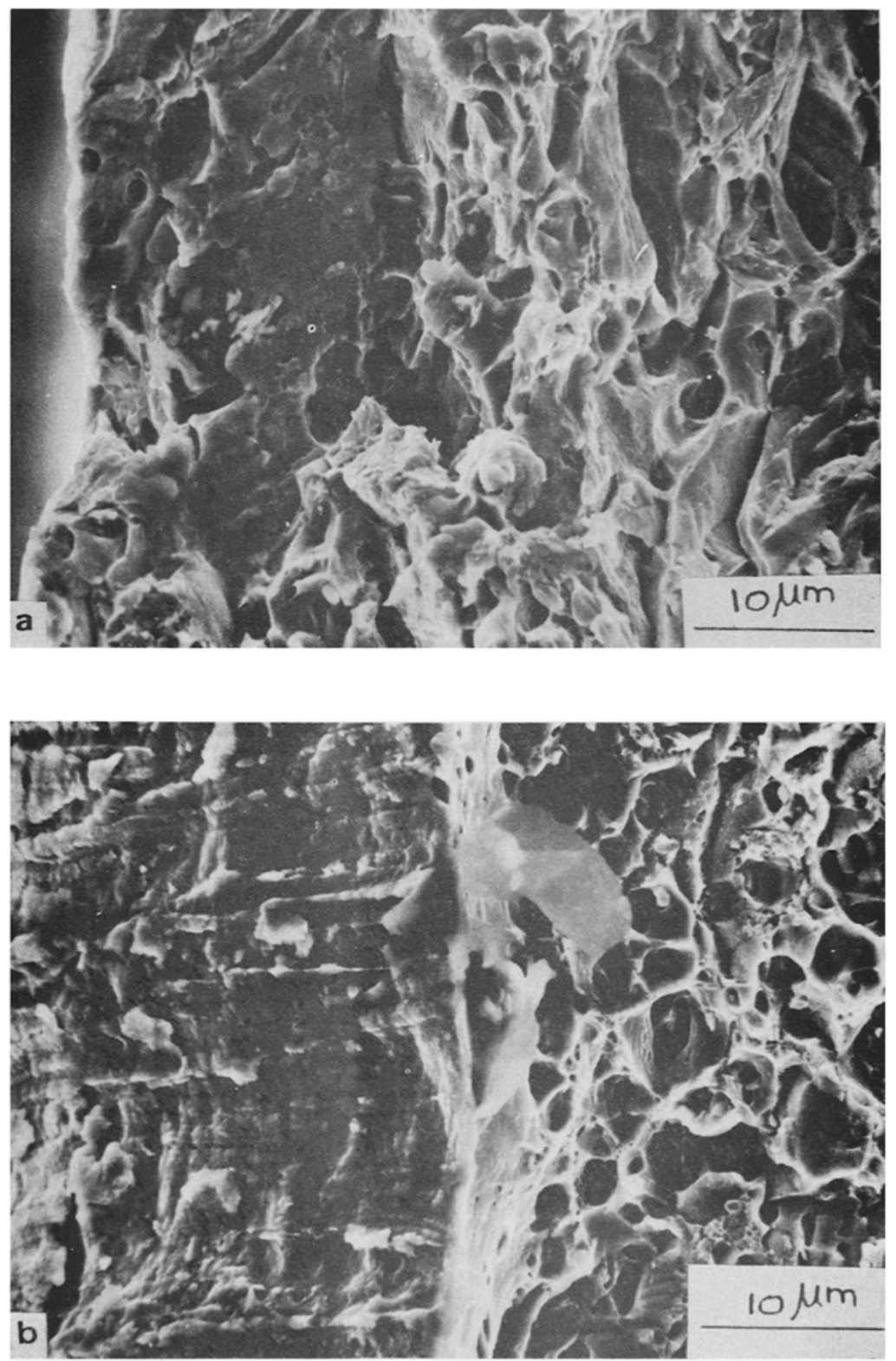

Figure 5. a. SEM fractograph of the edge region of the 2091-T351 sample charged at $7.5 \mathrm{~mA} / \mathrm{cm}^{2}$. Fracture surface exhibits a change in the mode of failure from brittle cleavage to a combination of planar slip facets with dimples from edge to inside. b. SEM fractograph of the edge region of the 2014-T 6 sample charged at $6 \mathrm{~mA} / \mathrm{cm}^{2}$. Fracture surface exhibits a change in the mode of failure from brittle cleavage to a combination of planar slip facets with dimples from edge to inside. 


\section{References}

Armacanqui M E and Oriani R A 1987 Mater. Sci. Engg. 91143

Hills D D, Williams D M and Mobley C E 1984 in Aluminium-lithium alloys II. Proc. Second Int. Al-Li Conf.,

TMS-AIME, Warrendale, PA. (eds) T H Sanders Jr and E A Starke Jr, p. 201

Hills D D and Williams D M 1984 in Aluminium-lithium alloys II. Proc. Second Int. Al-Li Conf., TMS-AIME, Warrendale. PA, (eds) T H Sanders Jr and E A Starke Jr, p. 201

Lavernia E J, Srivatsan T S and Mohamed F A 1990 J. Mater. Sci. 251137

Meletis E I and Huang W 1989 in Proc. Fifth Int. Al-Li Conf.. Williamsburg, Virginia, (eds) T H Sanders Jr and E A Starke Jr, Vol. III, p. 1309

Palmer I G, Lewis R E, Crooks D D, Starke E A Jrand Crooks R E 1984 in Aluminium-lithium alloy II, Proc. Second Int. Al-Li Conf. TMS-AIME, Warrendale, PA, (eds) T H Sanders Jr and E A Starke Jr, p. 91

Pickens J R 1985 J. Mater. Sci. 204247

Rajan Ambat and Dwarakadasa E S 1992 Corrosion Sci. 33681

Rivet F C and Swanson R E 1989 in Fifth Int. Al-Li Conf., Williamsburg, Virginia, (eds) T H Sanders Jr and E A Starke Jr, Vol. III, p. 1329

Sankaran K K and Grant N J 1980 in Aluminium-lithium alloys I. Proc. Int. Al-Li Conf.. TMS-AIME, Stone Mountain, Georgia, (eds) T H Sanders Jr and E A Starke Jr, Vol. I, p. 205

Sater J M and Sanders T H Jr 1989 in Proc. Fifth Int. Al-Li Conf., Williamsburg, Virginia, (eds) T H Sanders Jr and E A Starke Jr, Vol. III, p. 1217

Shin K S, Kim S S and Lee E W in Proc. Fifth Int. Al-Li Conf., Williamsburg, Virginia, (eds) T H Sanders Jr and E A Starke Jr, Vol. III, p. 1319

Watson J W, Shen Y Z and Meshi M 1988 Metall. Trans. A19 2299 